Article

\title{
Using Long-Term Removal Data to Manage a Crown-of-Thorns Starfish Population
}

\author{
Masako Nakamura ${ }^{1, *}$, Yoshimi Higa ${ }^{2}$, Naoki H. Kumagai ${ }^{3}$ and Ken Okaji ${ }^{4}$ \\ School of Marine Science and Technology, Tokai University, Shimizu, Shizuoka 424-8610, Japan \\ Onna Village Fisheries Cooperative, Onna, Okinawa 904-0414, Japan; mozuku@pony.ocn.ne.jp \\ National Institute for Environmental Studies, Tsukuba, Ibaraki 305-8506, Japan; nh.kuma@gmail.com \\ 4 Coralquest Inc., Atsugi, Kanagawa 243-0014, Japan; cab67820@pop06.odn.ne.jp \\ * Correspondence: mnakamura@tsc.u-tokai.ac.jp; Tel.: +81-54-334-0411
}

Academic Editors: Morgan Pratchett and Sven Uthicke

Received: 21 September 2016; Accepted: 14 November 2016; Published: 18 November 2016

\begin{abstract}
Background: Removal programs are effective strategies for short-term management of Crown-of-Thorns Starfish (Acanthaster spp.) populations, especially on a small scale. However, management programs are costly, and, in order to be effective, they must be based on local Acanthaster spp. population dynamics. We have developed simple models to predict the annual number of removable $A$. cf. solaris along the Onna coast of western central Okinawa Island, where chronic outbreaks have continued for several decades. Methods: The Onna coastal area was divided into five sectors, and annual abundance of small $A$. cf. solaris individuals was used to predict the total number of removable individuals of a cohort in each sector. Three models were developed, based on size class data collected by the Onna Village Fisheries Cooperative (OVFC) for 2003-2015, according to possible patterns of recruitment and adult occurrence. Using the best-fit models selected for each of the five sectors, the number of individuals that potentially escaped removal was calculated. Results: Best-fit models were likely to differ among the five sectors instead of small differences in the coefficients of determination. The models predict differences in the number of residual starfish among sectors; the northernmost sector was predicted to have a high number of residuals and the potential density of $A$. cf. solaris in the sector exceeded the outbreak criterion. Conclusions: These results suggest how to allocate resources to reduce the population of $A$. cf. solaris along the Onna coast in 2016. The OVFC implemented a control program for $A$. cf. solaris based on three model predictions.
\end{abstract}

Keywords: Acanthaster planci; coral; conservation; statistical model

\section{Introduction}

Outbreaks of the Crown-of-Thorns Starfish, Acanthaster spp., have been one of the major threats to coral communities in the Indo-Pacific region for more than a half-century [1]. A recent report showed that the Great Barrier Reef (GBR) has suffered heavy predation by $A$. cf. solaris for at least 27 years, resulting in a $42 \%$ loss of coral cover [2]. In a simulation, a $0.89 \% \mathrm{yr}^{-1}$ increase of coral cover was predicted in the absence of $A$. cf. solaris, despite the impacts of other disturbances to corals in the GBR [2]. This study highlighted the catastrophic influence of Acanthaster predation on coral communities. Similar to the GBR, other areas in the Indo-Pacific region have been damaged by unusually high densities of Acanthaster spp.: Countries within the Coral Triangle [3-5]: the Ryukyu Islands [6,7], Philippines [8], French Polynesia [9,10], and islands in the Indian Ocean [11].

Understanding causal factors of outbreaks of Acanthaster spp. is the principal weapon in the fight to prevent future coral loss. Decades of studies have determined that the major factor could be larval supply, which fluctuates drastically with phytoplankton availability [12]. However, neither of the factors controlling juvenile survival, nor other factors influencing outbreaks of Acanthaster spp., are 
fully understood [1]. Alternatively, direct control activities for removing adult Acanthaster spp. are commonly implemented in many localities in order to protect coral communities. Hand-collection and/or injection of lethal chemicals are the major methods of locally controlling Acanthaster spp. locally $[7,13,14]$. These control methods are usually ineffective if conducted as one-shot management attempts, because outbreaks of Acanthaster spp. normally occur for at least several years [6]. Therefore, continuing control activities of Acanthaster spp. could be proactive measures against future crises. However, removal programs are costly; thus, it is important to predict population dynamics of Acanthaster spp. to wisely allocate budget in order to develop management plans. If the programs are conducted without such plan, a budget might run out before resulting in a significant impact on the number of Acanthaster spp. That science-based budgeting is necessary to effectively control populations of Acanthaster spp. In Japan, local government budgets are based on a single-fiscal-year system, and are allocated according to the previous year's request. Because of this system, management programs were halted when the budget ran out, despite a population explosion of Acanthaster spp. [6]. Therefore, control methods must be strategically planned, with adequate budgets, based on accurate models of demographics of Acanthaster spp.

Quantification of densities and distributions of juvenile Acanthaster spp. are considered to be effective at predicting outbreaks $[15,16]$. Monitoring juvenile population dynamics could help to predict outbreaks $\sim 2$ years ahead because Acanthaster spp. reaches adulthood $(\sim 20 \mathrm{~cm})$ in two years $([17,18]$, Okaji unpublished data). Such field observations might contribute to effective management programs and might enable adequate budgeting by local governments $[15,16]$.

A long-term $A$. cf. solaris removal program has been conducted for more than 30 years along the west coast of Okinawa Island, Japan, by the Onna Village Fisheries Cooperative (OVFC, [7]). OVFC has been removing $A$. cf. solaris individuals along the Onna coast by hand-collection [7]. Removal data revealed that $A$. cf. solaris is widely occurring in the coral reef ecosystem of the Onna coast, suggesting that $A$. cf. solaris is likely to maintain chronically high densities in the area [7]. Moreover, in 2003, A. cf. solaris were sorted into 5 -cm size classes. Size class data suggested that multiple, successive recruitment events could potentially drive high $A$. cf. solaris population densities along the Onna coast [7]. As such, OVFC's removal data helps in understanding local A. cf. solaris population dynamics.

In this study, applying the idea of juvenile monitoring, we developed models to predict the number of removable $A$. cf. solaris individuals, which can be removed during the removal programs of OVFC, along the Onna coast using the OVFC data.

\section{Materials and Methods}

Size-class data of removed A. cf. solaris were collected beginning in 2003 at Maeda, Maeganaku, Minami Onna, Seragaki, and Afuso on the coast of Onna Village (Figure 1) by the OVFC. A. cf. solaris were manually removed by snorkeling and using tongs and other devices. The areas of removal were at $1-5 \mathrm{~m}$ depth during the daytime with $1-2 \mathrm{~h}$ surveys of both mornings and afternoons on selected days. The size of removed $A$. cf. solaris was determined with a diameter from the tip of one arm to the tip of the opposite arm. A. cf. solaris were divided into nine 5 - $\mathrm{cm}$ size classes from $0-<5 \mathrm{~cm}$ to $\geq 40 \mathrm{~cm}$, and individuals $\geq 40 \mathrm{~cm}$ were excluded from the analysis because any individuals of this size were found for 2003-2015.

We developed a model to predict the number of removable $A$. cf. solaris in the five sectors along the Onna coast using the size-class data of removed $A$. cf. solaris of the OVFC. In our model, the number of small individuals $(<15 \mathrm{~cm})$, estimated to be about one-year-old, was considered as the explanatory variable and used to predict the total number of removable individuals of that cohort. The growth rate of Acanthaster spp. in laboratory and field observations indicate that Acanthaster spp. reaches $3-15 \mathrm{~cm}$ in the first year, $18-25 \mathrm{~cm}$ in the second year, and $25-40 \mathrm{~cm}$ in the third year $([17,18]$, Okaji unpublished data). To choose an appropriate explanatory variable for the model, we considered three size classes of explanatory variables: $<5 \mathrm{~cm},<10 \mathrm{~cm}$, and $<15 \mathrm{~cm}$. However, only individuals of $<10 \mathrm{~cm}$ and $<15 \mathrm{~cm}$ were chosen as a potential explanatory variable because the number of removed 
individuals $<5 \mathrm{~cm}$ in diameter was low until 2010 ( 10 individuals per year collected along the Onna coast). In the analyses, we used complete cohort data, which comprised individuals of the 1st year $(<15 \mathrm{~cm}), 2$ nd year $(15-<25 \mathrm{~cm})$, and of the $3 \mathrm{rd}$ year $(25-<40 \mathrm{~cm})$. For example, when building up a complete cohort, size-class data were rearranged because size-class data for 2003, for example, consists of the 1st year individuals born in 2002, the 2nd year individuals born in 2001, and 3rd year individuals born in 2000, but a complete cohort of 2003 consists of removed individuals of $<15 \mathrm{~cm}$ in 2004, of $15-<25 \mathrm{~cm}$ in 2005 , and of $25-<40 \mathrm{~cm}$ in 2006. Therefore, we acquired complete cohort data from 2002 to 2012 , which were used for the analyses.
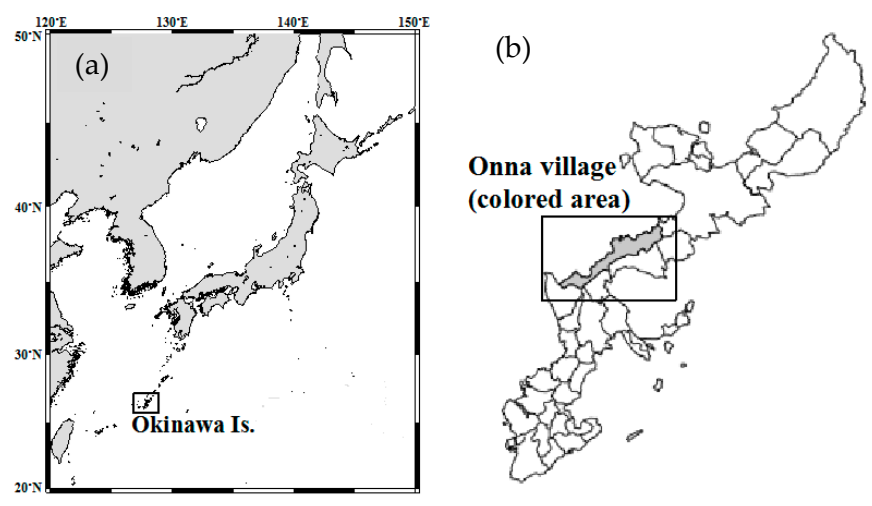

(c)

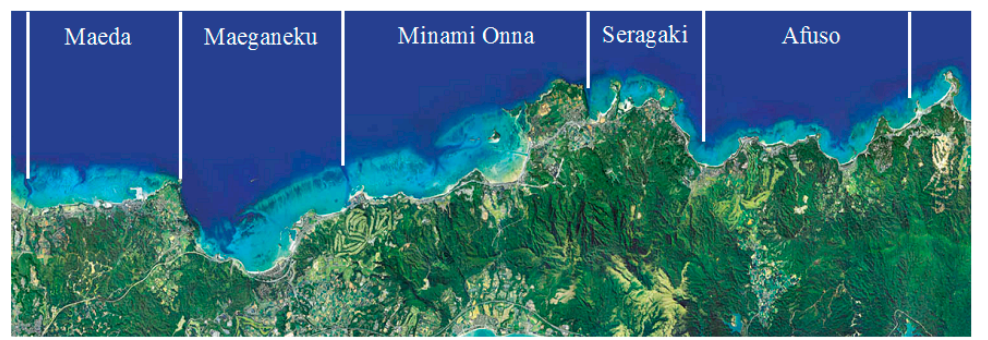

Figure 1. Study site maps: (a) Okinawa Island, Japan; (b) Onna Village on Okinawa Island; (c) five sectors, which are distinguished with channels, along the Onna coast.

We first constructed linear models to predict cohorts of $A$. cf. solaris as a function of the number of individuals of the 1st year (i.e., the size class $<10 \mathrm{~cm}$ or $<15 \mathrm{~cm}$, selected as a potential explanatory variable, as above) at each sector along the Onna coast, as follows: Cohort = First year individuals + First year individuals $x$ Sector. This model analyzed the relationship between the numbers of first-year A. cf. solaris removed (as First year individuals) and total numbers of removable individuals of the same cohort (as Cohort), and how the relationships differed among the five sectors (as First year individuals $x$ Sector). The Akaike information criterion (AIC) was used to estimate an optimum explanatory variable for the model; the size class $<10 \mathrm{~cm}$ or $<15 \mathrm{~cm}$. With the optimum variable, we examined the best-fit model for each of the five sectors along the Onna coast.

In selecting the best-fit model, we assumed three different cases for COTS population dynamics along the Onna coast with simple mathematical models; (1) linear, (2) logarithmic, and (3) exponential ones. These accord to Acanthaster juvenile and adult behavior. Acanthaster juveniles are negatively phototaxic, hiding in the shaded areas, e.g., crevices and holes of reefs, and are thus nocturnally active [19]. The negative phototaxis and nocturnality lessen with growth and the increase in density [19]. In addition, Acanthaster spp. move to shallow areas for the spawning [20]. According to these behavioral characteristics of Acanthaster spp., Case 1: The linear model indicates that larvae consistently settled, developed, and were eventually removed in areas where OVFC conducted $A$. cf. solaris removal. Case 2: The logarithmic model indicates that the areas of settlement have a number of places for hiding for A. cf. solaris. In this context, "places for hiding" contains two meanings; large area with many hiding places for juveniles, and large area where fishermen could not patrol the whole area due to 
limited time and manpower, thus, $A$. cf. solaris could escape from removal. This model could show a maximum number of removable individuals with limited time and manpower. Case 3: The exponential model indicates that areas of settlement have relatively less places to hide from fishermen, that is, relatively narrow areas, where fishermen could cover all areas when patrolling. Therefore, $A$. cf. solaris appear easily in shallower areas while growing, and then, eventually, be removed. Therefore, we selected the best-fit model for each of the five sectors. We first estimated and tested coefficients for the three models. The estimated total removable individuals of a cohort were then calculated using the estimated coefficients for each of the three models. Residuals were tested for normality with the Shapiro-Wilk test. Then we selected the models showing the largest coefficients of determination among the fitted models (best-fit) for each of the five sectors, provided that the residuals indicated data normality. For the best-fit models, 95\% confidence intervals were also calculated. With the best-fit models, we predicted the total numbers of removable and non-removable individuals (difference between the predicted total removable individuals and the already-removed individuals of the 1st and/or the 2nd year), for the cohorts 2013 and 2014.

\section{Results and Discussion}

Size-frequency distributions of removed $A$. cf. solaris demonstrated abundance maxima for all five sectors along the Onna coast over 13 years. The abundant size classes were consistently from $<15 \mathrm{~cm}$ to $<25 \mathrm{~cm}$ for all sectors (Figure 2), indicating successive recruitments in the five sectors along the Onna coast over many years $[7,21]$. Size class abundance data also demonstrate the importance of larval recruitment in maintaining the $A$. cf. solaris population along the Onna coast.

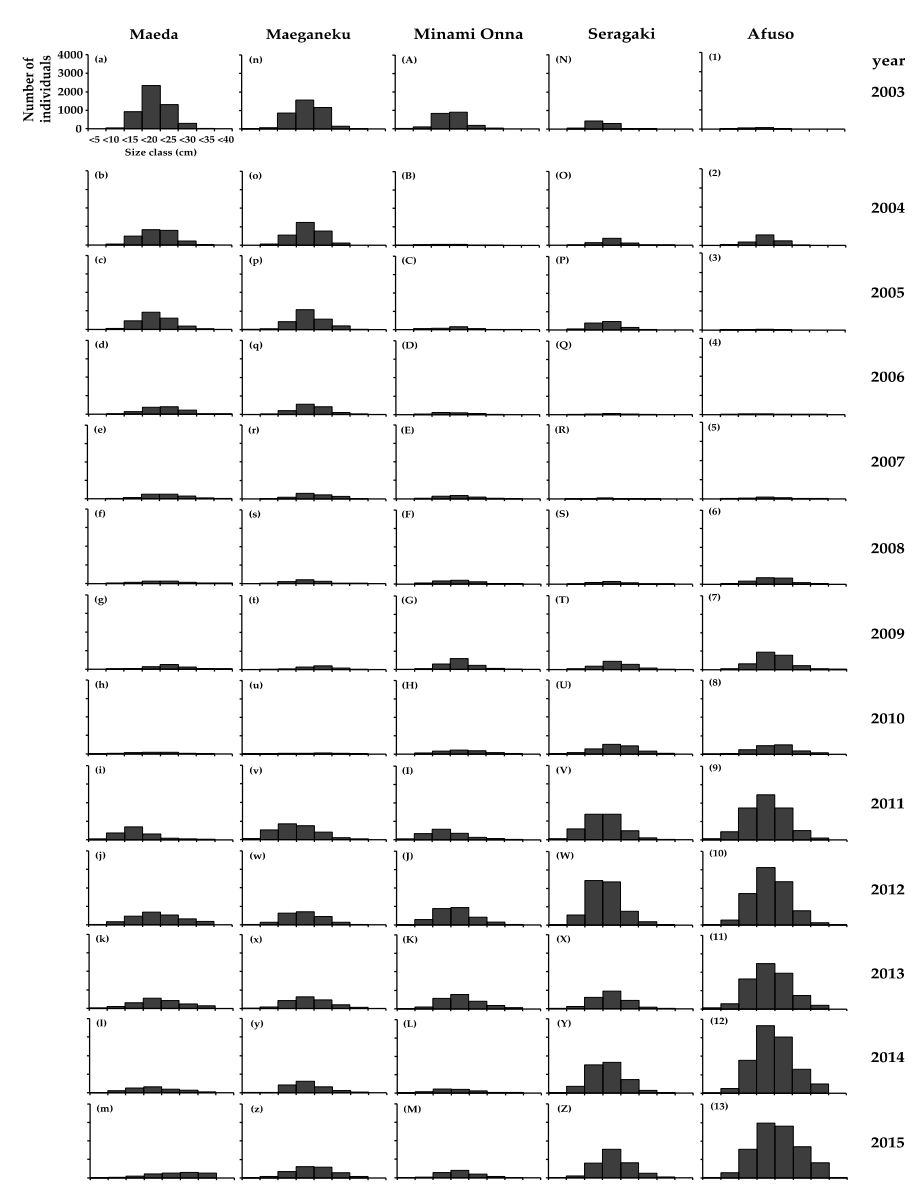

Figure 2. Size-frequency distributions of Acanthaster cf. solaris for five sectors along the Onna Coast, Okinawa, Japan, over 13 years. (a-m), Maeda; (n-z), Maeganeku; (A-M), Minami Onna; (N-Z), Seragaki; (1-13), Afuso. 
Annual fluctuation in removed $A$. cf. solaris demonstrated a south-to-north change of sectors of more abundant $A$. cf. solaris along the coast (Figure 2). Maeda (Figure 2a-m) and Maeganeku (Figure 2n-z), the two most southern sectors, showed relatively high removal numbers in 2003 and a gradual decrease until 2010, following this, there was another increase in 2011. Minami Onna showed an abrupt decline from 2003 to 2004 and then a gradual increase to 2012 (Figure 2A-M). The numbers of removed starfish at Seragaki (Figure 2N-Z) and Afuso (Figure 21-13) were relatively low until 2008, followed by an increase from 2009. This pattern could be related to northeastward onshore currents that prevail along the Onna coast during the $A$. cf. solaris larval dispersal period [22].

Removal data suggested the importance of juveniles for $A$. cf. solaris population maintenance along the Onna coast. Based on the linear model, numbers of both $<10 \mathrm{~cm}$ and $<15 \mathrm{~cm}$ individuals accurately predicted the total number of removable individuals belonging to a given cohort (Tables 1 and 2). However, the model, using only starfish $<15 \mathrm{~cm}$ as an explanatory variable, was a better model according to AIC (Tables 1 and 2). Using $<15 \mathrm{~cm}$ individuals as an explanatory variable, best-fit models were likely to differ among sectors, instead of having small differences in the coefficients of determination (Tables 3 and 4, Figure 3 and Figure S1). The relationship between the number of first year starfish and the total removable individuals belonging to a cohort in Afuso was optimally fitted to the logarithmic model. At Seragaki, Maeganeku, and Maeda, the linear model provided the best fit. Minami Onna was likely to be described by the exponential model. Small differences in the coefficients of determination suggested a necessity for continuation of removal programs in order to accumulate more data. Moreover, the present study demonstrated that we could predict the number of removable individuals of $A$. cf. solaris in a certain area using a simple and low-cost calculation using long-term removal size-class data.

Table 1. Parameter estimates of the predictive model for the total number of removable individuals in the same cohort (first to third year individuals) as a function of the number of $<10 \mathrm{~cm}$ individuals designated as first-year Acanthaster cf. solaris removed at each sector along the Onna Coast, Japan. $\mathrm{AF}=$ Afuso, $\mathrm{MO}=$ Minami Onna, $\mathrm{MG}=$ Maeganeku, $\mathrm{MD}=$ Maeda. $p$-value: significance level based on $t$-value.

\begin{tabular}{ccccc}
\hline & Estimate & Std. Error & $\boldsymbol{t}$-value & $\boldsymbol{p}$-value \\
\hline Intercept & 1035 & 208.5 & 4.961 & $8.83 \times 10^{-6}$ \\
1st year class $(<10 \mathrm{~cm})$ & 6.355 & 1.486 & 4.277 & $8.74 \times 10^{-5}$ \\
1st year class $(<10 \mathrm{~cm})$ _AF & 14.81 & 2.321 & 6.384 & $5.98 \times 10^{-8}$ \\
1st year class $(<10 \mathrm{~cm})$ _MO & -3.278 & 2.810 & -1.167 & 0.249 \\
1st year class $(<10 \mathrm{~cm})$ MG & -2.946 & 2.454 & -1.201 & 0.236 \\
1st year class $(<10 \mathrm{~cm}) \_$MD & -2.421 & 2.974 & -0.814 & 0.420 \\
AIC & 948.1 & & & \\
\hline
\end{tabular}

Table 2. Parameter estimates of the predictive model for the total number of removable individuals in the same cohort (first to third year individuals) as a function of the number of $<15 \mathrm{~cm}$ individuals designated as first-year Acanthaster cf. solaris removed at each sector along the Onna Coast, Japan. $\mathrm{AF}=$ Afuso, $\mathrm{MO}=$ Minami Onna, $\mathrm{MG}=$ Maeganeku, $\mathrm{MD}=$ Maeda. $p$-value: significance level based on $t$-value.

\begin{tabular}{ccccc}
\hline & Estimate & Std. Error & $t$-value & $p$-value \\
\hline Intercept & 637.4 & 161.6 & 3.943 & $25.5 \times 10^{-5}$ \\
1st year class $(<15 \mathrm{~cm})$ & 1.680 & 0.243 & 6.927 & $8.61 \times 10^{-9}$ \\
1st year class $(<15 \mathrm{~cm})$ _AF & 2.552 & 0.325 & 7.841 & $3.35 \times 10^{-10}$ \\
1st year class $(<15 \mathrm{~cm})$ _MO & -0.475 & 0.493 & -0.964 & 0.340 \\
1st year class $(<15 \mathrm{~cm})$ _MG & 0.267 & 0.475 & 0.562 & 0.577 \\
1st year class $(<15 \mathrm{~cm})$ MD & 0.367 & 0.533 & 0.688 & 0.495 \\
AIC & 905.8 & & & \\
\hline
\end{tabular}


Table 3. Coefficient of determination for three models for the five sectors along the Onna coast, Japan. The largest values are in bold. n.a. indicates the model that did not ensure normality.

\begin{tabular}{cccc}
\hline \multirow{2}{*}{ Sector } & \multicolumn{3}{c}{ Models } \\
\cline { 2 - 4 } & Linear & Logarithmic & Exponential \\
\hline Afuso & n.a. & $\mathbf{0 . 8 0 8}$ & 0.791 \\
Seragaki & $\mathbf{0 . 7 5 3}$ & 0.716 & 0.549 \\
Minami Onna & 0.720 & 0.687 & $\mathbf{0 . 7 2 3}$ \\
Maeganeku & $\mathbf{0 . 7 7 9}$ & 0.739 & 0.567 \\
Maeda & $\mathbf{0 . 9 1 1}$ & 0.897 & 0.783 \\
\hline
\end{tabular}

Table 4. Best model for all sectors along the Onna coast for predicting total removable cohort (Y) membership based upon the number of individuals $<15 \mathrm{~cm}(X)$.

\begin{tabular}{cc}
\hline Sector & Best Model \\
\hline Afuso & $\mathrm{Y}=2218 \log (\mathrm{X})-8484$ \\
Seragaki & $\mathrm{Y}=1.615 \mathrm{X}+758.4$ \\
Minami Onna & $\mathrm{Y}=422.2 \times 1.001^{\mathrm{X}}$ \\
Maeganeku & $\mathrm{Y}=1.955 \mathrm{X}+631.2$ \\
Maeda & $\mathrm{Y}=2.277 \mathrm{X}+470.0$ \\
\hline
\end{tabular}
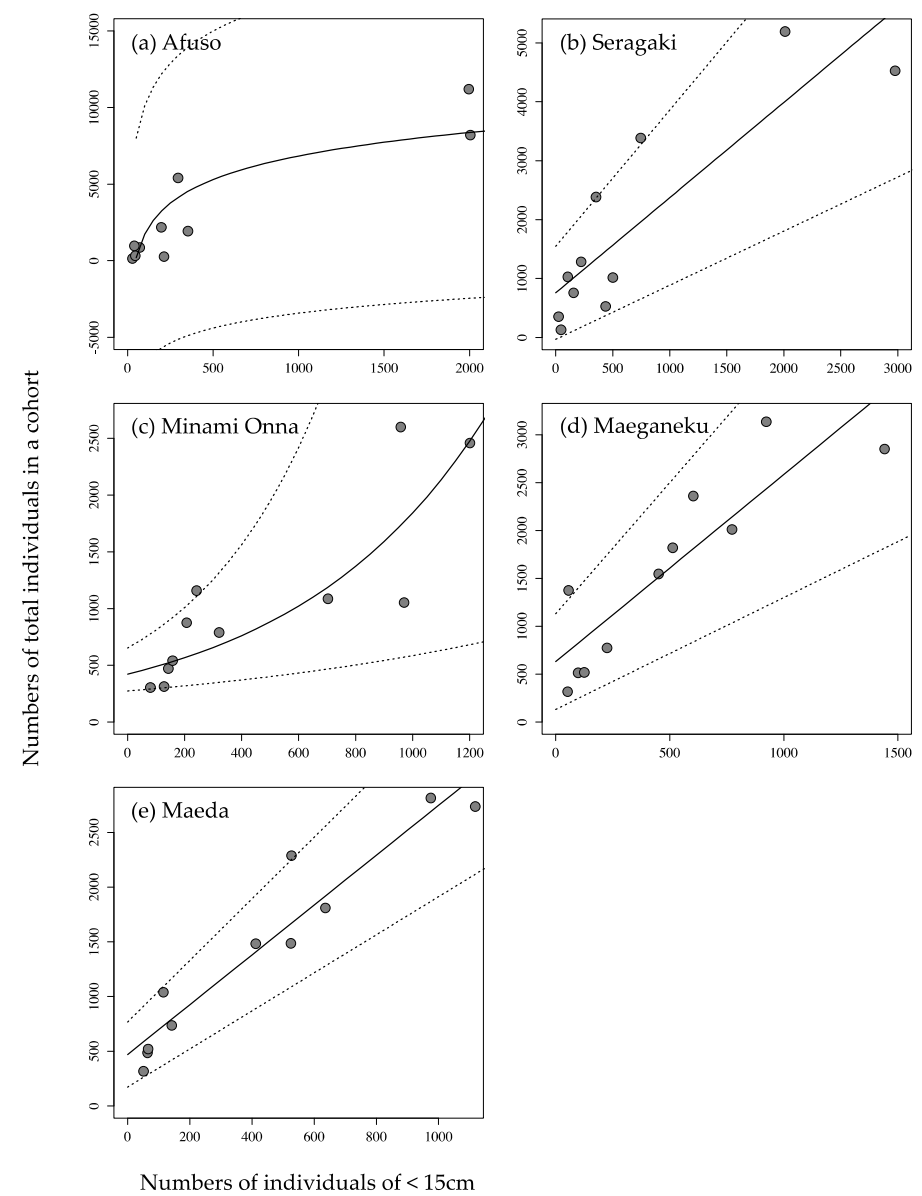

Figure 3. Best-fit model with $95 \%$ confidence intervals for the relationship between the numbers of removed individuals $<15 \mathrm{~cm}$ and the total number of removed individuals in the same cohort of Acanthaster cf. solaris for five sectors along the Onna coast, Okinawa, Japan. (a) Afuso; (b) Seragaki; (c) Minami Onna; (d) Maeganeku; (e) Maeda. 
Using these models, the total predicted removable individuals (Figure S2) and the predicted removable individuals that escaped removal were calculated for the cohorts 2013 and 2014 (Table 5). There were potentially uncaptured individuals in the 2013 cohort in Afuso and Maeda after two years of removal and in the 2014 cohort in all sectors after one year of removal. This implies that two years of concerted eradication efforts might not be sufficient to eradicate A. cf. solaris in Afuso and Maeda. According to the predictive models, control programs should allocate more effort in Maeda and especially in Afuso, which might have relatively larger hiding places for $A$. cf. solaris from the OVFC members than the other sectors. Indeed, the model predicted that as many as 6350 individuals from the 2014 cohort could remain in Afuso (Table 5). Additionally, the area of removal in Afuso is about 238.8 ha, which suggests there could be 26.5 A. cf. solaris ha ${ }^{-1}$ in Afuso, exceeding the outbreak criterion of 15 individuals ha ${ }^{-1}$ [23].

Table 5. The number of individuals that escaped removal, predicted from the best-fit models for the cohorts 2013 and 2014 for five sectors along the Onna coast, Okinawa, Japan.

\begin{tabular}{ccc}
\hline \multirow{2}{*}{ Sector } & \multicolumn{2}{c}{ Number of Individuals that Escaped Removal } \\
\cline { 2 - 3 } & Cohort 2013 & Cohort 2014 \\
\hline Afuso & 577 & 6350 \\
Seragaki & 0 & 1315 \\
Minami Onna & 0 & 357 \\
Maeganeku & 0 & 1057 \\
Maeda & 508 & 644 \\
\hline
\end{tabular}

The OVFC's efforts enable the prediction of the number of uncaptured A. cf. solaris at each of the five sectors along the Onna coast using predictive models. Therefore, the OVFC can plan how to allocate removal efforts along the coast in order to further reduce the number of starfish in January 2016. The OVFC implemented a control program based on these models since January 2016 with the main objective being to remove remaining adults before the July spawning season [24]. Such effort could reduce successful fertilization in subsequent seasons and potentially control the number of A. cf. solaris [14].

\section{Conclusions}

Predictive models based on long-term removal data could contribute to planning a strategic management program for $A$. cf. solaris along the Onna coast. Our data suggest that simple models can be applied to local control efforts. Five-centimeter size class data could be useful for selecting the best predictive model. These models are useful as a rough standard for $A$. cf. solaris management programs, and should facilitate budgetary planning for $A$. cf. solaris control.

Supplementary Materials: The following are available online at www.mdpi.com/1424-2818/8/4/24/s1, Figure S1: Relationship between the numbers of individuals $<15 \mathrm{~cm}$ and of total individuals in the same cohort of Acanthaster cf. solaris for five sectors along the Onna coast, Okinawa, Japan, with three different models. Black line, linear model; blue line, logarithmic model; red line, exponential model, Figure S2: Total removable individuals of cohort 2013 (Red) and 2014 (Blue) predicted from the best-fit models for the relationship between the numbers of individuals of $<15 \mathrm{~cm}$ and total individuals in the same cohort of Acanthaster cf. solaris for five sectors along the Onna coast, Okinawa, Japan with observed values (Grey).

Acknowledgments: We are very grateful to the members of the Onna Village Fisheries Cooperative. We thank Steven D. Aird for editing our manuscript.

Author Contributions: Y.H. and K.O. conceived and designed the experiments; M.N. and N.H.K. analyzed the data; M.N. wrote the paper.

Conflicts of Interest: The authors declare no conflicts of interest. 


\section{References}

1. Pratchett, M.S.; Caballes, C.F.; Rivera-Posada, J.A.; Sweatman, H.P.A. Limits to understanding and managing outbreaks of Crown-of-Thorns starfish (Acanthaster spp.). Oceanogr. Mar. Biol. 2014, 52, 133-200.

2. De'ath, G.; Fabricius, K.E.; Sweatman, H.; Puotinen, M. The 27-year decline of coral cover on the Great Barrier Reef and its causes. Proc. Natl. Acad. Sci. USA 2012, 109, 17995-17999. [CrossRef] [PubMed]

3. Pratchett, M.S.; Schenk, T.J.; Baine, M.; Syms, C.; Baird, A.H. Selective coral mortality associated with outbreaks of Acanthaster planci L. in Bootless Bay, Papua New Guinea. Mar. Environ. Res. 2009, 67, 230-236. [CrossRef] [PubMed]

4. Baird, A.H.; Pratchett, M.S.; Hoey, A.S.; Herdiana, Y.; Campbell, S.J. Acanthaster planci is a major cause of coral mortality in Indonesia. Coral Reefs 2013, 32, 803-812. [CrossRef]

5. Plass-Johnson, J.G.; Schwieder, H.; Heiden, J.; Weiand, L.; Wild, C.; Jompa, J.; Ferse, S.C.A.; Teichberg, M. A recent outbreak of crown-of-thorns starfish (Acanthaster planci) in the Spermonde Archipelago, Indonesia. Reg. Environ. Chang. 2015, 15, 1157-1162. [CrossRef]

6. Yamaguchi, M. Acanthaster planci infestations of reefs and coral assemblages in Japan: A retrospective analysis of control efforts. Coral Reefs 1986, 5, 23-30. [CrossRef]

7. Nakamura, M.; Okaji, K.; Higa, Y.; Yamagawa, E.; Mitarai, S. Spatial and temporal population dynamics of the crown-of-thorns starfish, Acanthaster planci, over a 24-year period along the central west coast of Okinawa Island, Japan. Mar. Biol. 2014, 161, 2521-2530. [CrossRef]

8. Bos, A.R. Crown-of-thorns outbreak at the Tubbataha Reef UNESCO World Heritage Site. Zool. Stud. 2010, $49,124$.

9. Adjeroud, M.; Michonneau, F.; Edmounds, P.J.; Chancerelle, Y.; Lison de Loma, T.; Penin, L.; Thibaut, L.; Vidal-Dupiol, J.; Salvat, B.; Galzin, R. Recurrent disturbances recovery trajectories, and resilience of coral assemblages on a South Central Pacific reef. Coral Reefs 2009, 28, 775-780. [CrossRef]

10. Kayal, M.; Vercelloni, J.; de Loma, T.L.; Bosserelle, P.; Chancerelle, Y.; Geoffroy, S.; Stievenart, C.; Michonneau, F.; Penin, L.; Planes, S.; et al. Predator crown-of-thorns starfish (Acanthaster planci) outbreak, mass mortality of corals, and cascading effects on reef fish and benthic communities. PLOS ONE 2012, 7, e47363. [CrossRef] [PubMed]

11. Roche, R.C.; Pratchett, M.S.; Carr, P.; Turner, J.R.; Wagner, D.; Head, C.; Sheppard, C.R.C. Localized outbreaks of Acanthaster planci at an isolated and unpopulated reef atoll in the Chagos Archipelago. Mar. Biol. 2015, 162, 1695-1704. [CrossRef]

12. Fabricius, K.E.; Okaji, K.; De'ath, G. Three lines of evidence to link outbreaks of the corwn-of-thorns seastar Acanthaster planci to the release of larval food limitation. Coral Reefs 2010, 29, 593-605. [CrossRef]

13. Bostrom-Einarsson, L.; Rivera-Posada, J. Controlling outbreaks of the coral-eating crown-of-thorns starfish using a single injection of common household vinegar. Coral Reefs 2016, 35, 223-228. [CrossRef]

14. Bos, A.R.; Gumanao, G.S.; Mueller, B.; Saceda-Cardoza, M.M.E. Management of crown-of-thorns sea star (Acanthaster planci L.) outbreaks: Removal success depends on reef topography and timing within the reproduction cycle. Ocean Coast Manag. 2013, 71, 116-122. [CrossRef]

15. Yokochi, H. The early detection of Acanthaster outbreaks by monitoring the algae-eating juvenile starfish. Midoriishi 1998, 9, 12-14. (In Japanese)

16. Research Institute for Subtropical Regions. Manual for Monitoring of Juvenile Crown-of-Thorns Starfish; Research Institute for Subtropical Regions: Naha, Japan, 2006; p. 29. (In Japanese)

17. Yamaguchi, M. Growth of juvenile Acanthaster planci (L) in the laboratory. Pac. Sci. 1974, 28, 123-138.

18. Lucas, J.S. Growth, maturation and effects of diet in Acanthaster planci (L.) (Asteroidae) and hybrids reared in the laboratory. J. Exp. Mar. Biol. Ecol. 1984, 79, 129-147. [CrossRef]

19. Birkeland, C.; Lucas, J.S. Acanthaster planci: Major Management Problems of Coral Reefs; CRC Press, Inc.: Florida, FL, USA, 1990.

20. Babcook, R.C.; Mundy, C.N. Reproductive biology, spawning and field fertilization rates of Acanthaster planci. Aust. J. Mar. Freshw. Res. 1992, 43, 525-534. [CrossRef]

21. Pratchett, M.S. Dynamics of an outbreak population of Acanthaster planci at Lizard Island, northern Great Barrier Reef (1995-1999). Coral Reefs 2005, 24, 453-462. [CrossRef] 
22. Nakamura, M.; Kumagai, N.H.; Sakai, K.; Okaji, K.; Ogasawara, K.; Mitarai, S. Spatial variability in recruitment of acroporid corals and predatory starfish along the Onna coast, Okinawa, Japan. Mar. Ecol. Prog. Ser. 2015, 540, 1-12. [CrossRef]

23. Moran, P.J.; De'ath, G. Estimates of the abundance of the crown-of-thorns starfish Acanthaster planci in outbreaking and non-outbreaking populations on reefs within the Great Barrier Reef. Mar. Biol. 1992, 113, 509-515. [CrossRef]

24. Yasuda, N.; Ogasawara, K.; Kajiwara, K.; Ueno, M.; Oki, K.; Taniguchi, H.; Kakuma, S.; Okaji, K.; Nadaoka, K. Latitudinal differentiation in the reproduction patterns of the crown-of-thorns starfish Acanthaster planci through the Ryukyu Island Archipelago. Plankton Benthos Res. 2010, 5, 156-164. [CrossRef]

(C) 2016 by the authors; licensee MDPI, Basel, Switzerland. This article is an open access article distributed under the terms and conditions of the Creative Commons Attribution (CC-BY) license (http://creativecommons.org/licenses/by/4.0/). 